\title{
Material Properties of Acetylated Jute-Mat Composites
}

\author{
T. Al-Mobarak ${ }^{\mathrm{a}}$, M. F. Mina ${ }^{\mathrm{a}}$, and M. A. Gafur ${ }^{\mathrm{b}}$ \\ ${ }^{\mathrm{a}}$ Department of Physics, Faculty of Engineering, Bangladesh University of Engineering and \\ Technology, Dhaka-1000, Bangladesh \\ ${ }^{\mathrm{b}}$ PP \& PDC, Bangladesh Council of Scientific and Industrial Research, Dhaka-1205, Bangladesh \\ Received 4 September 2012, accepted in final revised form 20 December 2012
}

\begin{abstract}
Jute-mat (JM) reinforced polyvinylchloride (PVC) composites were prepared with various contents of acetylated and non-acetylated JM by heat-pressed method at $160{ }^{\circ} \mathrm{C}$ to obtain a neat PVC (NPVC), untreated PVC-JM composites (UC) and treated PVC-JM composites (TC). Structural, mechanical, surface morphological and thermal properties of a NPVC and a series of UC and TC were characterized by Fourier transform infrared (FTIR) spectrometry, mechanical test and differential thermal analyses (DTA). Water intake (WI) measurements of these samples were also performed. FTIR spectra show distinct absorption peaks for NPVC, UC and TC, suggesting a modified surface texture of JM fiber. While the NPVC does not show any water absorption, the UC exhibit higher WI than TC, indicating that the hydrophilic moiety of JM is filled up by the acetyl group. Tensile strength, flexural strength, Young's modulus and tangent modulus of TC are observed to be higher than those of NPVC and UC. Surface micrographs reveal a better adhesion between acetylated JM and PVC than between non-acetylated JM and PVC. The decomposing temperature of TC is observed to be higher than that of NPVC and UC. Enhancement of various properties of acetylated JM-PVC composites is elaborately discussed in this paper.
\end{abstract}

Keywords: Acetylation; Jute-mat; Polyvinylchloride; Composites; Thermal properties; Mechanical properties.

๑) 2013 JSR Publications. ISSN: 2070-0237 (Print); 2070-0245 (Online). All rights reserved.

doi: http://dx.doi.org/10.3329/jsr.v5i1.11798 $\quad$ J. Sci. Res. 5 (1), 13-23 (2013)

\section{Introduction}

Jute fiber is a soft natural fiber extracted from jute plants and is extensively grown in Southeast Asian countries. This fiber is largely used in the production of twins, upholstery, padding and mat-marketing, fancy articles such as purses, wall-hanging, table mats, bags, cloths and so on. Although it is used in manufacturing cheap house-hold commodities, its potential and delicate application is still under research. Use of jute fiber as reinforcement in the fabrication of polymer-jute composites raised great interest and

\footnotetext{
*Corresponding author: minamd.forhad@yahoo.com,mfmina@phy.buet.ac.bd
} 
expectations among materials scientists and engineers in the last decades [1-9]. The primary advantages of using this fiber as an additive in the production of polymer composites are that it has biodegradability, low cost, low density, non-abrasive nature, high possibility of filling levels, low energy consumption, high specific properties, wide varieties and above all a generation of agriculture-based economy [1, 3, 9]. Despite of its great advantages and scopes, jute fiber has two major drawbacks that preclude its promising uses in composites fabrication. One of these disadvantages is that jute fiber is hydrophilic in nature, and its moisture absorption reduces its durability. The other one is its poor adhesion with synthetic polymers. Therefore, it is necessary to modify the fiber surface without genetic manipulation in order to alleviate hydrophilicity of the fiber so that its adhesion with the hydrophobic moiety can be improved.

A fair number of research works have been carried out without surface modifications of jute fiber by chemical treatment [10-13]. In these studies, a decrease of tensile strength, flexural strength, Young's modulus has been observed. The authors have claimed that this decrease is most likely due to the poor adhesion between jute fiber and polymer matrix. Thereafter, chemical treatments of the fiber have been focused, because effect of chemical treatments develops roughness of fiber surface, thereby increasing surface area available for surface contact with polymer matrix. Effect of alkali treatment of jute fiber on mechanical properties of jute-reinforced polymer composites has been studied by many researchers who have shown a modification fiber-surface texture and an enhancement of mechanical properties considerably [13-15]. Apart from alkali treatment, expensive compatibilizers or coupling agents like silane and maleic anhydride are reported to use for the improvement of adhesion between fiber and polymer [16-18]. In order to make a good adhesion between modified fiber and polymer molecules, the possibility of acid treatment can not be ignored. Therefore, an alternative way of surface modification using acetic acid is performed in this study to fabricate jutemat/poly(vinylchloride) composites, which have then been subjected to physical, structural, mechanical, and thermal characterizations. In this article, the results obtained from various characterizations are presented in details.

\section{Experimental Details}

\subsection{Materials}

The raw materials used in this investigation are jute-mat (JM) and polyvinylchloride (PVC) sheet, purchased from local market. $2 \mathrm{wt} \%$ acetic acid $\left(\mathrm{CH}_{3} \mathrm{COOH}\right)$ solutions were prepared for acetylation of JM, maintaining a liquor ratio of 1:20 (1 gm JM in $20 \mathrm{gm}$ solution). JM's were immersed in this solution at $30^{\circ} \mathrm{C}$ for $1 \mathrm{hr}$ and then removed. They were washed several times with fresh water, dried at room temperature $\left(30^{\circ} \mathrm{C}\right)$ and then at $105^{\circ} \mathrm{C}$ in an oven.

A series of JM-reinforced PVC composites were prepared with and without acetylated fibers. For fabrication of composites, PVC sheet and JM are embedded and heat pressed at 
$160^{\circ} \mathrm{C}$. The ratios of PVC:JM in the composites were maintained as 2:1, 1:2, 2:2 and 3:2, where their weight ratio was maintained. The samples finally obtained are neat PVC sheet, PVC-JM composites without chemical treatment of JM and PVC-JM composites with acetylated JM. The neat PVC, chemically untreated JM-PVC composites and chemically treated JM-PVC composites are respectively abbreviated here-in-after as NPVC, UC and TC.

\subsection{Water intake}

Water intake (WI) of the various samples was performed. The test specimen was cut in a size of $6 \mathrm{~cm}$ length, $2 \mathrm{~cm}$ width and $\approx 0.3 \mathrm{~cm}$ thickness. The cut sample was kept in a woven at $80^{\circ} \mathrm{C}$ for $24 \mathrm{hr}$ and immediately weighed. Let this weight be $W_{i}$. The sample was then immersed in distilled water of $23^{\circ} \mathrm{C}$ and kept for $24 \mathrm{hr}$, taken out from water, wiped by a cloth and then weighed. Let this weight be $W_{f}$. Then the amount of water intake was calculated by the following formula:

$$
\mathrm{WI}(\%)=\left[\frac{W_{f}-W_{i}}{W_{f}}\right] \times 100,
$$

The above procedures were repeated for $48,72,96$ and $120 \mathrm{hr}$ with other samples. It is noteworthy that the cut sides of the samples were coated with araldite to prevent from penetrating water into the sample.

\subsection{Fourier transforms infrared spectroscopic measurements}

Fourier-transform infrared (FTIR) spectra of the samples were recorded at room temperature by using a double beam IR spectrophotometer (SHIMADZU, FTIR-8900 spectrophotometer, JAPAN) in the wave number range of $400-4000 \mathrm{~cm}^{-1}$. For these measurements, the samples were cut into very small pieces which were then mixed with $\mathrm{KBr}$ for recording the FTIR spectra in the transmittance (\%) mode.

\subsection{Mechanical testing}

Tensile strength $(T S)$, percentage of elongation-at-break $[E B(\%)]$ and Young's modulus $(Y)$ of the samples were measured by a universal testing machine [Hounsfield UTM $10 \mathrm{KN}$; ASTM D-638-98] at a crosshead speed of $0.001 \mathrm{~m}-\mathrm{min}^{-1}$, keeping a gauge length of $0.06 \mathrm{~m}$. Flexural strength, $(F S)$, flexural strain $[F B(\%)]$, and tangent modulus $(G)$ were also measured by the same apparatus, keeping a distance of $0.064 \mathrm{~m}$ between two supports on which the samples were placed to employ load. Five samples of each composition were used in the mechanical testing. 


\subsection{Scanning electron microscopy}

Fractured surface of the NPVC, UC and TC were studied by a scanning electron microscope (SEM) [Philips XL 30, Netherlands]. Each sample was cut from the region of fracture with an appropriate size for the study of surface structure by a SEM. The sample surface was coated with a thin layer of gold by sputtering prior to the SEM measurement. The surface micrographs of the fractured samples were taken at maximum operating voltage of $30 \mathrm{kV}$ of the apparatus.

\subsection{Thermal measurements}

Thermal properties of the samples were monitored by a differential thermal analyzer (DTA) [Seiko-Ex-STAR-6300, Japan]. The measurements using DTA were carried out from $37-600^{\circ} \mathrm{C}$ at a heating rate of $20^{\circ} \mathrm{C} / \mathrm{min}$ under nitrogen gas flow. The DTA traces give melting and degradation temperatures of the samples as determined from the exotherm versus temperature curves.

\section{Results and Discussion}

\subsection{Water intake}

Fig. 1 shows the dependence of WI (\%) on soaking time for NPVC, UC and TC with PVC:JM=2:1. WI (\%) increases rapidly with time and levels off at $120 \mathrm{hr}$ for UC and TC, while it is constant with time for NPVC. The NPVC and JM are respectively hydrophobic and hydrophilic in nature for which the NPVC practically shows no WI with time. On the other hand, WI is higher in UC due to the hydrophilic nature of JM. Thus WI is found slower in TC than in UC, suggesting a development of hydrophobic nature of the acetylated composite. The maximum WI obtained in this study is $8.25 \mathrm{wt} \%$, which is in a good agreement with the published report [19].

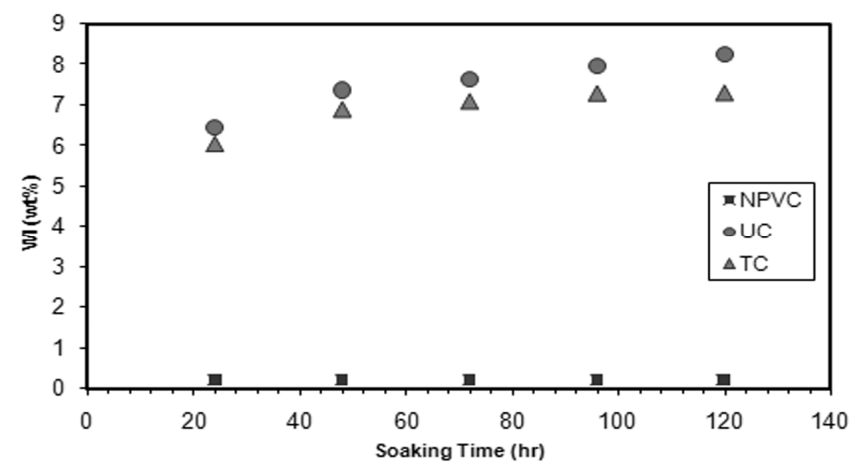

Fig. 1. Variation of water absorption with soaking time for the NPVC, UC and TC with PVC:JM=2:1 


\subsection{FTIR structural analyses}

Fig. 2 shows the FTIR spectra of the NPVC, UC and TC, recorded as a transmittance versus wave-number in the range of 500-4000 $\mathrm{cm}^{-1}$. For NPVC, two wide bands appear at 600 and $1100 \mathrm{~cm}^{-1}$; two peaks appear at 2379 and $2900 \mathrm{~cm}^{-1}$. Besides, zigzag peaks are also apparent in the range $1300-1900 \mathrm{~cm}^{-1}$, with a noticeable variation from the zigzag peaks observed in case of UC and TC. The absorption peaks in the range 600-700 $\mathrm{cm}^{-1}$ may be attributed to $\mathrm{C}-\mathrm{Cl}$ stretching, while in the range $900-1200 \mathrm{~cm}^{-1}$ may be assigned to $\mathrm{C}-\mathrm{C}$ stretching of PVC molecules. The absorption peaks appearing at 1210, 1439, 1550, 1600, 1760 and $1900 \mathrm{~cm}^{-1}$ may correspond to numerous $\mathrm{CH}$ modes such as cis-C-H wagging, trans-C-H wagging, $\mathrm{C}-\mathrm{H}$ rocking, $\mathrm{C}-\mathrm{H}$ stretching, $\mathrm{CH}_{2}$ deformation, $\mathrm{C}=\mathrm{C}$ stretching of the PVC molecules. The broad band at $2900 \mathrm{~cm}^{-1}$ may be due to $\mathrm{C}-\mathrm{H}$ stretching of alkene. The peak positions obtained for PVC agree with the published results [20-22].

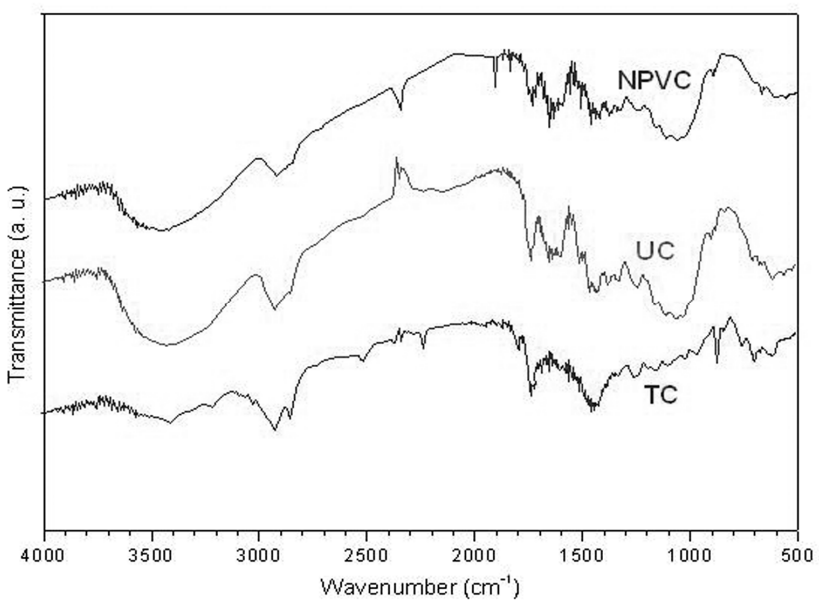

Fig. 2. FTIR spectra of NPVC, UC and TC.

In case of UC, the shape of the peak at $2379 \mathrm{~cm}^{-1}$ is different from that at $2379 \mathrm{~cm}^{-1}$ of NPVC. Moreover, the peak at $1900 \mathrm{~cm}^{-1}$ of NPVC does not appear in the spectrum of UC. These results suggest that some of the molecular vibrations of neat PVC are restricted after inclusion of JM. In the spectrum of TC, a number of additional peaks with both broad and sharp band are seen. A broad peak around $2900 \mathrm{~cm}^{-1}$ may be due to the $\mathrm{C}-\mathrm{H}$ stretching in alkene. The absorption band at $2820 \mathrm{~cm}^{-1}$ may be due to the presence of hydrogen bonded carboxylic acid $(\mathrm{COOH})$. The next absorption band at $2500 \mathrm{~cm}^{-1}$ is probably due to the presence of alkynes $(C=C)$. The absorption band at $2360 \mathrm{~cm}^{-1}$ is due to the presence of carboxyl group $(\mathrm{C}=\mathrm{O})$. The absorption bands from $1300-1800 \mathrm{~cm}^{-1}$ is probably fingerprint region. In case of $\mathrm{UC}$ and $\mathrm{TC}$, the appearance of new bands demonstrates the adhesion of JM with PVC. Some of these additional peaks coming after the inclusion of JM conform to those reported in the literature [7, 23]. The chemical 
reaction between $\mathrm{JM}$ and $\mathrm{CH}_{3} \mathrm{COOH}$ results in $\mathrm{JM}-\mathrm{O}-\mathrm{C}=\mathrm{O}-\mathrm{CH}_{3}$ [21]. Both $\mathrm{COOH}$ and $\mathrm{C}=\mathrm{O}$ absorption bands are present in the spectra. Therefore, the adhesion between acetylated JM and PVC molecules is confirmed from the FTIR spectra.

\subsection{Mechanical properties}

$T S, E B(\%)$ and $Y$ of various samples are plotted in Figs. 3(a)-(c). Fig. 3(a) shows TS for NPVC, untreated JM (UJM), treated JM (TJM), UC and TC with various PVC:JM.

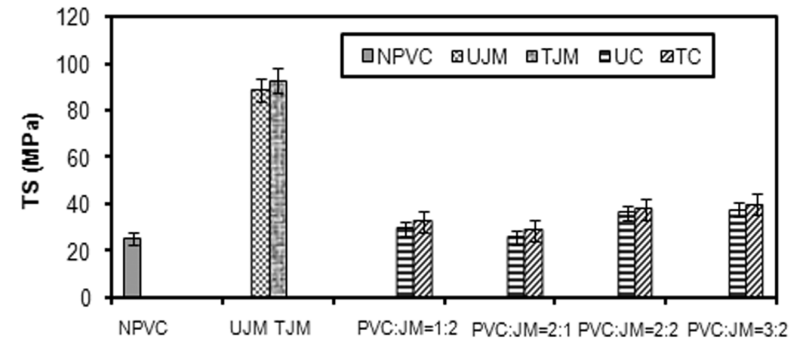

PVC:JM

Fig. 3. (a) TS values for NPVC, UC and TC composites with various ratios of PVC and JM.

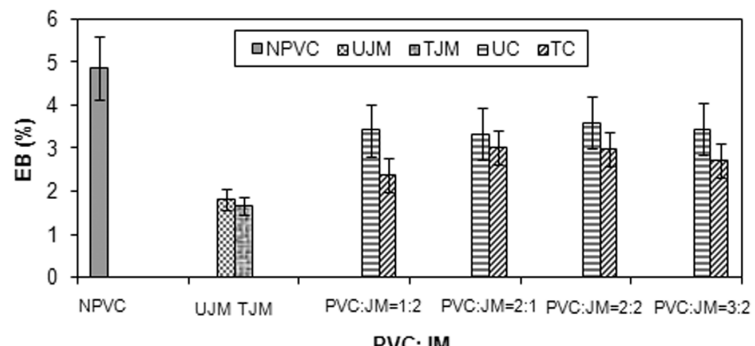

Fig. 3. (b) $E B(\%)$ values for NPVC, UC and TC composites with various ratios of PVC and JM.

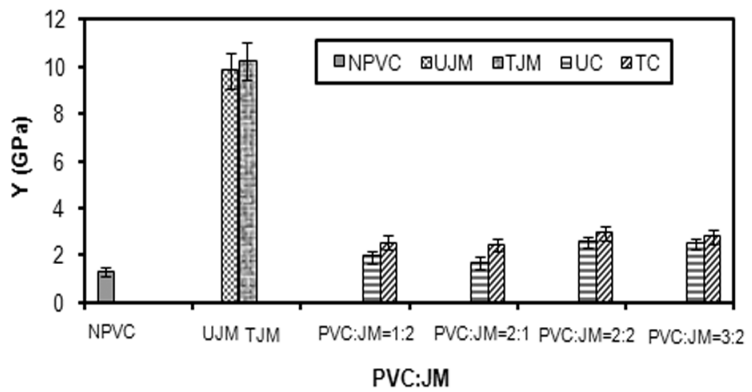

Fig. 3. (c) $Y$ values for NPVC, UC and TC composites with various ratios of PVC and JM.

TS values for NPVC, UJM and TJM are found to be 26,89 and $93 \mathrm{MPa}$, respectively. TS of the UC and TC are found to increase with increase of jute content. In each PVC:JM 
ratio, the TS value for TC is higher than that of the UC. The highest TS value of $38 \mathrm{MPa}$ and $40 \mathrm{MPa}$ are respectively obtained for UC and TC with PVC:JM=3:2. Because of the chemical treatment, the swelling behavior of the fiber surface is expected to increase, resulting in rough surface that helps develop better interfacial adhesion between the JM and PVC matrix. This adhesion may be the basis of TS increase in TC. $E B(\%)$ for the NPVC, UJM, TJM, UC and TC with different PVC:JM ratios are presented in Fig. 3(b) and is observed to show the highest value for NPVC among other samples investigated, indicating a soft property of PVC. For TC, $E B(\%)$ is lower than that of UC. After acetylation of JM, an increase of roughness between JM and PVC is established. While the PVC molecules in NPVC can readily slip past each other, they find difficulties to slip in case of UC and TC, resulting fracture at relatively lower values of $E B(\%)$. Fig. 3(c) shows the $Y$ values for the NPVC, UJM, TJM, UC and TC. The UJM and TJM show the highest $Y$ value, which for TC are higher than those for NPVC and UC. A larger $Y$ value for UC than that for NPVC may arise from higher $Y$ value of JM than PVC. Thus, the addition of fibers increases the stiffness of the resulting composite and fiber-surface treatment enhances this stiffness. While the maximum $Y$ for NPVC is about $1.3 \mathrm{GPa}$, it is about 2.5 GPa in UC and even higher in TC, suggesting better performance due to chemical treatment. Figs. 4(a)-(c) represents $F S, F B(\%)$, and $G$ values for various samples. The trend of changes of $F S, F B(\%)$ and $G$ are similar to that of $T S, E B(\%)$ and $Y$.

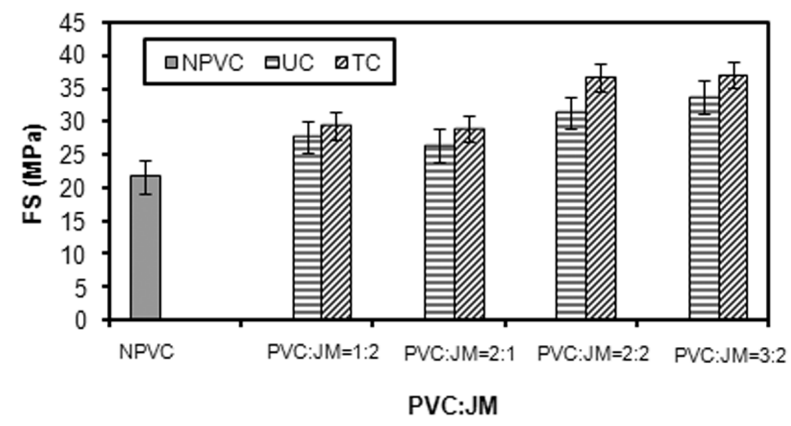

Fig. 4. (a) FS values for NPVC, UC and TC composites with various ratios of PVC and JM.

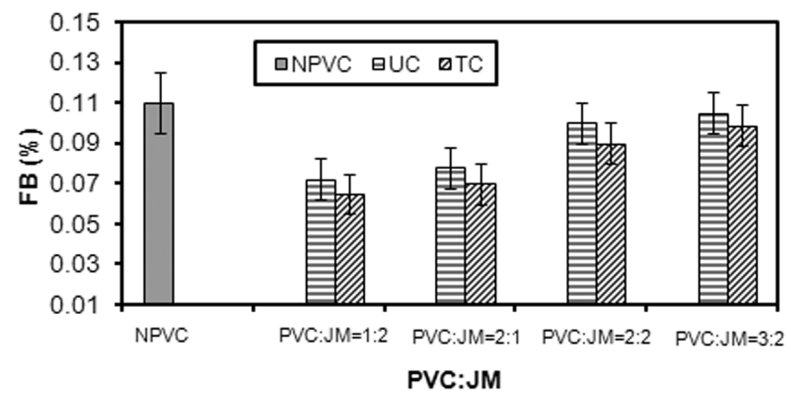

Fig. 4. (b) FB (\%) values for NPVC, UC and TC composites with various ratios of PVC and JM. 


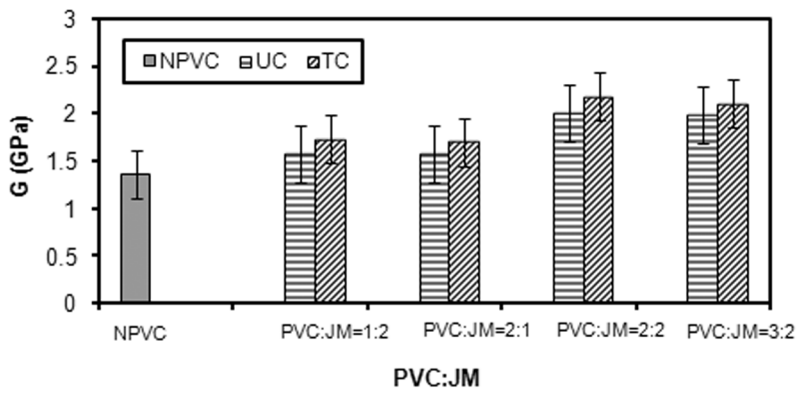

Fig. 4. (c) $G$ values for NPVC, UC and TC composites with various ratios of PVC and JM.

\subsection{Surface morphology}

Fig. 5 shows SEM micrographs of the fractured surface of NPVC, UC and TC. For NPVC [Fig. 5(a)] the surface is unsmooth and contains huge number of flaws. For PVC:JM=2:1, the micrograph shows that most of the JM fibers are found to be pulled out from the matrix [Fig. 5(b)], resulting a poor adhesion between these two components. For TC (PVC:JM=2:1), a few fibers are observed to be pulled out from the matrix and most of them are in good adhesion with PVC [Fig. 5(c)], showing a better adhesion between JM and PVC than UC.
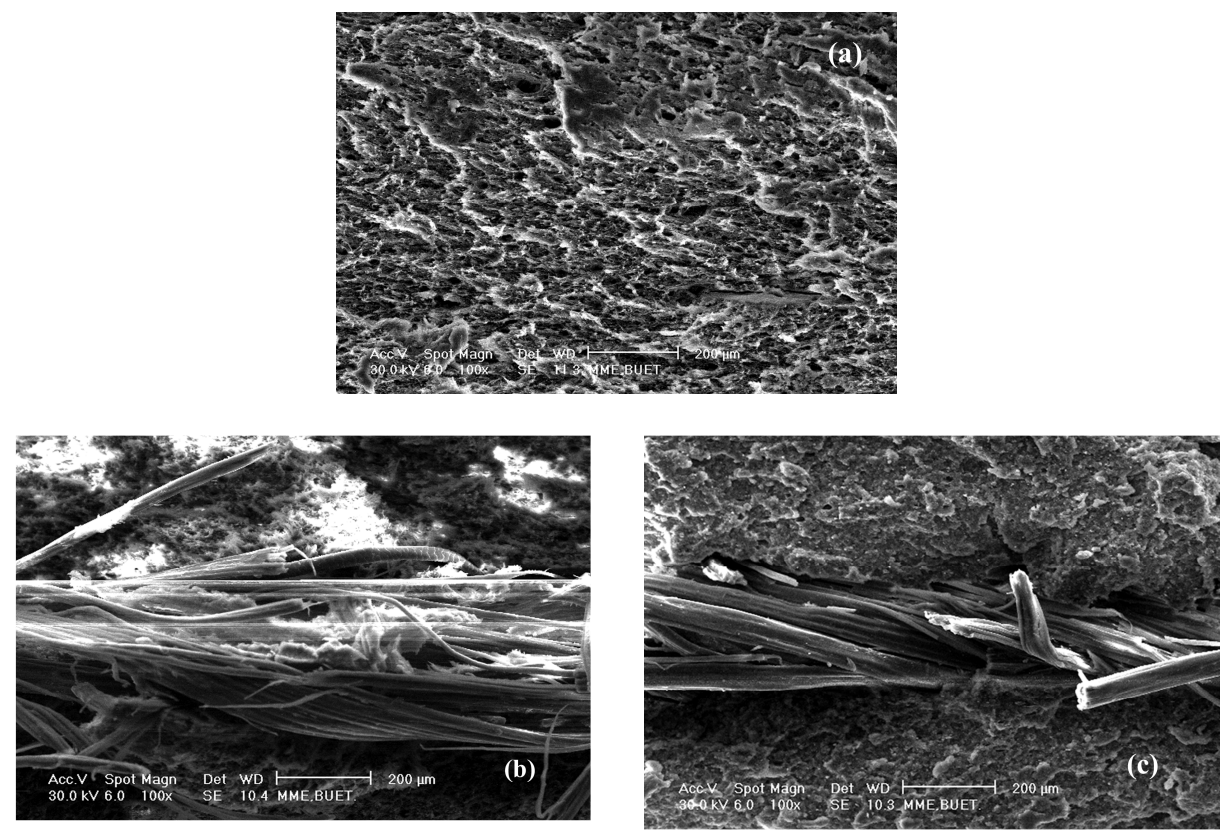

Fig. 5. SEM micrographs of the fractured surfaces of (a) NPVC, (b) UC and (c) TC. 


\subsection{Thermal Properties}

Fig. 6 represents a comparison of DTA curves for NPVC, UC and TC with various ratios of PVC and JM. Decomposing temperatures of the samples are obvious from the endothermic peaks of the thermograms. The degradation temperature for the NPVC is found to be $291^{\circ} \mathrm{C}$ and that for UC (PVC:JM=3:2) and TC (PVC:JM=3:2) is $295^{\circ} \mathrm{C}$ and $300^{\circ} \mathrm{C}$, respectively. The increase of degradation temperatures reveals a good impact of JM and PVC. Similar behavior as that observed in case of acetylated JM reinforced composites of the present study is also reported in the case of jute fiber reinforced shellac composites [24].

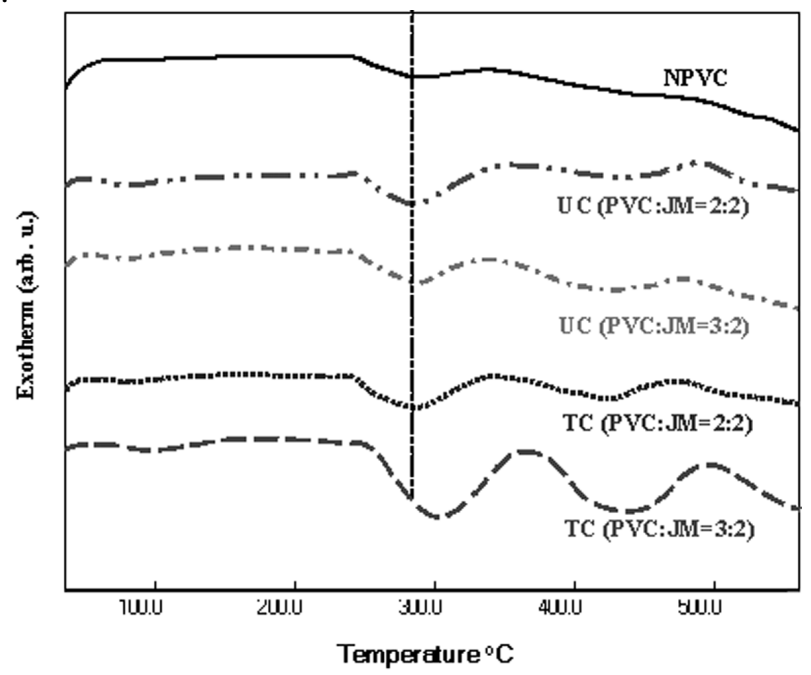

Fig. 6. A comparison of DTA curves for NPVC and UC and TC with various ratios of PVC and JM.

\section{Conclusions}

On the basis of results the following conclusions may be drawn:

a. FTIR analyses have confirmed the surface modification of JM by acetylation, showing the absorption band of carboxyl group $(\mathrm{C}=\mathrm{O})$. This is a bond developed when JM is acetylated, resulting in a hydrophobic character of JM for which its adhesion property with PVC increases.

b. The NPVC does not intake water due to the hydrophobic nature of PVC molecules, whereas the UC exhibit higher water-intake than the TC, indicating that UJM is more hydrophilic in nature than TJM.

c. The mechanical properties such as TS, FS, YM and TM of the TC are observed to be more than those of UC and NPVC, suggesting better performance due to acetylation of JM. 
d. Surface micrographs indicate a better adhesion between TJM and PVC than that of between UJM and PVC.

e. The melting and decomposing temperatures of the TC are observed to be higher from that of NPVC and UC.

\section{Acknowledgement}

The authors are thankful to the Pilot Plant \& Process Development Center (PP \& PDC), BCSIR, Dhaka for providing data of FTIR, and Department of Materials and Metallurgical Engineering, BUET for providing data of SEM.

\section{References}

1. A. K. Mohanty, M. Misra, and L. T. Drzal, J. Polym. Environ. 10 (1), 19 (2002). http://dx.doi.org/10.1023/A:1021013921916

2. A. K. Mohanty, M. Misra, and L. T. Drzal (Tailor and Francis, CRC Press, Singapore, 2005) pp. 1-875.

3. G. Bogoeva-Gaceva, M. Avella, M. Malinconico, A. Buzarovska, A. Grozdaov, G. Gentile, and M. E. Ericco, Polym. Compos. 28 (1), 98 (2007). http://dx.doi.org/10.1002/pc.20270

4. A. K. Mohanty, M. A. Khan, S. Sahoo, and G. Hinrichen, J. mat. Sci. 35 (10), 2589 (2000). http://dx.doi.org/10.1023/A:1004723330799

5. A. K. Mohanty, M. Misra, and L. T. Drzal, Composite Interfaces 8 (5), 313 (2000). http://dx.doi.org/10.1163/156855401753255422

6. A. K. Mohanty, M. Misra, and L. T. Drzal, J. Adhes. Sci. Technol., 16 (8), 999 (2002). http://dx.doi.org/10.1163/156856102760146129

7. X. Y. Liu, and G. C. Dai, e-Polym. Lett. 1, 299 (2007).

8. M. A. Khan, G. Hinrichsen, and L. T. Drzal, J. Mat. Sci. Lett. 20, 1711 (2001). http://dx.doi.org/10.1023/A:1012489823103

9. M. J. Miah, M. A. Khan, and R. A. Khan, J. Sci. Res. 3 (2), 249 (2011). http://dx.doi.org/10.3329/jsr.v3i2.6763

10. T. N. Gowda, A. C. B. Naidu, and R. Chhaya, Compos. Sci. Tech., 30, 277 (1999).

11. S. Wang, S. Adanur, and B. Z. Jang, Composite, Part-B: Eng. 28 (3), 215 (1997). http://dx.doi.org/10.1016/S1359-8368(96)00042-X

12. P. J. Roe, and M. P. Ansell, J. Mat. Sci. 20, 4015 (1985). http://dx.doi.org/10.1007/BF00552393

13. D. Ray, B. K. Sarkar, S. Das, and A. K. Rana, Compos. Sci. Tech. 62, 7 (1997).

14. D. Ray, B. K. Sarkar, and N. R. Bose, Composite 23 (A), 233 (2002).

15. J. Gassan, and A. K. Bledzki, Compos. Sci. Tech., 59, 1 (1997).

16. M. A. Khan, M. F. Mina, L. T. Drzal, $3^{\text {rd }}$ International wood \& natural fiber composites symposium, September 19-20, 2000, Kassel, Germany, p. 5-1-2.

17. N. Sombatsompop, C. Yotinwattanakumtorn, and C. Thongpin, J. Appl. Polym. Sci. 97, 475 (2005). http://dx.doi.org/10.1002/app.21765

18. A. K. Mohanty, M. Misra, and L. T. Drzal, J. Mat. Sci. Lett. 21, 1885 (2002). http://dx.doi.org/10.1023/A:1021577632600

19. A. A. A. Rashdi, S. M. Sapuan, M.M.H.M. Ahmad, A. Khalina, J. Food Agricul. Environ. 7, 908 (2009).

20. Z. Xiaojiang, H. H. Pu, Y. Yanheng, L. A. Junfeng, J. Polym. Sci., Part C: Polym. Lett. 27, 223 (1989). http://dx.doi.org/10.1002/pol.1989.140270702

21. S. Rajendran, M. R. Prabhu, and M. U. Rani, Int. J. Electro-chem. Sci. 3, 282 (2008).

22. S. Rajendran and T. Uma, Ionics 7, 122 (2001). http://dx.doi.org/10.1007/BF02375478 
23. D. Ray and B. K. Sarkar, J. Appl. Polym. Sci. 80, 1013 (2001).

http://dx.doi.org/10.1002/app.1184

24. M. A. Khan, S. Ghoshal, R. Khan, S. A. Pervin, and A. Mustafa, Chem. Technol. 2, 232 (2008). 